\title{
Parentesco reconfigurado no espaço da adoção*
}

\author{
Barbara Yngvesson ${ }^{* *}$
}

\section{Resumo}

Nesse artigo, inspiro-me em pesquisas realizadas na Suécia, Índia, Colômbia, Equador, Bolívia, Chile e Estados Unidos, entre 1995 e 2004, para enfocar o que Laurel Kendall descreve como "a plasticidade assim como a força do parentesco idiomático" no contexto da adoção transnacional. Tanto na Europa como na América do Norte, adoções transnacionais (que tendem a ser transraciais, dado que a maioria das crianças adotadas vem de regiões não-européias) complicam o projeto de "imitar a natureza", pois em muitas dessas adoções a "diferença" entre os pais adotivos e a criança é evidente. O adotado oriundo da Ásia, da África ou da América Latina que vive numa família euroamericana representa um paradoxo de pertencimento no contexto global onde o transnacionalismo, ao mesmo tempo, afirma $e$ transgride as fronteiras da nação-estado.

Palavras-chave: Adoção Transnacional, Parentesco Idiomático, Migrações, Identidade Étnica, Pertencimento Nacional.

\footnotetext{
" Recebido para publicação em maio de 2007, aceito em agosto de 2007 (Tradução: Cláudia Fonseca; Revisão: José Fonseca).

** Antropóloga, professora em Hampshire College, Amherst, Massachussetts. byngvesson@hampshire.edu
}

cadernos pagu (29), julho-dezembro de 2007:111-138. 
Parentesco reconfigurado no espaço da adoção

Refiguring Kinship in the Space of Adoption

\begin{abstract}
In this article, I draw on research carried out in Sweden, India, Colombia, Ecuador, Bolivia, Chile, and the United States between 1995-2004 to focus on what Laurel Kendall describes as "the plasticity as well as the power of idiomatic kinship" in the context of transnational adoption. In both Europe and North America, transnational adoptions (which have tended to be cross-racial, in the sense that the majority of adopted children come from nonEuropean regions of the globe) complicate the project of "imitating nature", since in many of these adoptions, the "difference" between adopted child and parent is obvious. The adoptee from Asia, Africa, or Latin America in an Euro-American home represents the ultimate paradox of belonging in a global context where transnationalism both affirms and breaches the borders of the nation-state.
\end{abstract}

Key Words: Transnational Adoption, Idiomatic Kinship, Migration, Ethnic Identity, National Belonging. 
Barbara Yngvesson

Ao antecipar o futuro de famílias semelhantes à minha, considero a plasticidade assim como a força do parentesco idiomático como um sinal de esperança (Laurel Kendall, 2005:177).

\section{Mães (de nascimento) e filhas}

Em maio de 2006, visitei Estocolmo para dar uma série de conferências sobre minha pesquisa em torno da adoção internacional na Suécia. ${ }^{1}$ Enquanto estava lá, passei bastante

\footnotetext{
1 A pesquisa que fundamentou este artigo foi financiada pela National Science Foundation (projetos \#SES-9113894 and \#SBR-9511937) e por auxílios fornecidos por Hampshire College. Abrange o período de 1995 a 2004 e inclui duas fases. Durante a primeira fase, iniciada em 1995 e que continuou até 1999, enfoquei as transações entre agências de adoção e orfanatos ou abrigos, no âmbito de instrumentos regulatórios como a Convenção dos Direitos da Criança das Nações Unidas (1989) e a Convenção de Haia para a Proteção de Crianças e a Cooperação em relação à Adoção Internacional (1993). Com base no Centro de Adoção na Suécia (CA), pude conduzir entrevistas com o pessoal executivo e assistir a conferências e oficinas com os funcionários do CA e profissionais locais de adoção em La Paz (1995), Banglore (1995), Quito (1996), New Delhi (1996) e Hong Kong (1996), assim como na Suécia. Viajei com representantes do CA para realizar visitas em abrigos para crianças e adolescentes na Ásia e na América Latina. Também entrevistei diretores de abrigos, assistentes sociais, juristas e outras pessoas nos países "doadores" de crianças que estavam envolvidas na colocação de crianças adotadas no exterior. Ao mesmo tempo e além dessa primeira fase de pesquisa, de 1997 a 2004, assisti eventos e reuniões organizados por adultos adotados na Suécia, li memórias e olhei vídeos e documentários escritos ou realizados por eles, ou nos quais eles eram protagonistas. Também realizei entrevistas com uma série de jovens adultos adotados entre 16 e 30 anos de idade. Tratava-se de homens e mulheres nascidos na Etiópia, no Chile, na Colômbia, na Índia ou na Coréia. Todas as entrevistas seguiam um roteiro aberto enfocando ou a experiência de crescer como filho adotado na Suécia ou a visita ao país (ou à família) de origem. Algumas entrevistas foram realizadas uma única vez com uma só pessoa. Outras consistiam em conversas junto com dois, três ou quatro adultos adotados. Algumas foram realizadas com adolescentes ou adultos adotados junto com seus pais adotivos. Em um caso, agi como intérprete numa reunião entre uma menina adotada, sua mãe adotiva e sua mãe de nascimento. Uma série de entrevistas com adotados nascidos na Etiópia envolveu entrevistas mais extensas, registradas durante cinco a seis anos, tratando de voltas repetidas
} 
Parentesco reconfigurado no espaço da adoção

tempo com diversos adultos que tinham sido adotados, pessoas que eu tinha entrevistado ao longo dos oito anos anteriores sobre as viagens que tinham feito para conhecer seus países $e$, em alguns casos, suas famílias de nascimento. Desde minha visita anterior, algumas dessas pessoas tinham dado à luz, algo que, para elas - que foram "abandonadas" por suas mães pouco tempo depois do nascimento -, possui significado emocional particular. Duas das jovens mulheres, uma com quase 30 e outra com 30 e poucos anos, tinham filhas de cinco semanas de idade. Uma morava com seu "sambo" (um parceiro que, embora não casado, possui status legal na Suécia), a outra estava casada com o pai da criança. Falei com cada uma delas sobre sua experiência de gravidez e parto.

Uma das mulheres, Katarina, que nasceu no Chile no início dos anos 80, explicou que não sentia nenhum desejo de ter filhos até reencontrar sua mãe de nascimento em 2004. Essa reunião, iniciada com um encontro desconfortável em um hotel no Sul do Chile, onde Katarina, seu namorado e sua mãe adotiva estavam hospedados, foi concluída com uma visita à mãe de nascimento na casa onde esta morava com seu marido e filhos. Katarina descreveu o momento poderoso em que seus sentimentos sobre parto mudaram. Segurando um álbum de fotos da viagem, ela me mostrou uma foto sua com a mãe de nascimento. A mãe, com o braço esquerdo sobre os ombros de Katarina, pousava a mão direita na barriga da filha. Katarina explicou que a mãe lhe cochichava palavras carinhosas, tocando-a primeiro no peito $e$ depois na barriga, apertando-a contra si. "Naquele instante,

para a nação ou família de nascimento. Nessas entrevistas, explorei os significados do retorno $e$ as implicações da reunião com a família de nascimento para a relação dos adultos adotados com seus pais ou países adotivos. Finalmente, em 1998, participei de uma viagem de "retorno às raízes" (roots trip) organizada pelo Centro de Adoção. Durante duas semanas, servi de intérprete espanhol-sueco para doze famílias suecas com crianças adotadas do Chile. Depois dessa viagem, na qual o grupo visitou Santiago e Temuco, no sul do Chile, visitei as famílias em Estocolmo, Goteborg e outras cidades para aprender mais sobre as consequências da viagem para pais e filhos. 
pensei, "claro que posso ter um filho"'. Ao voltar para a Suécia, ficou grávida "sem querer".

A Suécia possui um sistema excelente de atendimento prénatal e Katarina disse que, à medida que sua gravidez avançava, fazia planos para um parto que descreveu como uma "cesariana voluntária". As cesarianas na Suécia são muito menos freqüentes do que nos Estados Unidos e esse tipo de cesariana (escolhida apesar de não existir nenhuma indicação médica) é pouco comum. Os profissionais do centro de saúde que freqüentava, preocupados com sua atitude, tentaram persuadi-la a mudar de idéia, mas ela manteve sua opção. Além disso, resolveu não amamentar seu nenê, preferindo alimentá-lo com mamadeira. Alguns dias mais tarde, numa reunião com outros adultos adotados, ela se referiu à filha como uma "criança de mamadeira".

Enquanto estávamos sentadas no parque e eu registrava a conversa, Katarina balançava o luxuoso carrinho do nenê cada vez que ele começava a choramingar. Ela falou de sua decepção por o bebê não lhe fazer sentir conectada nem com sua família adotiva, nem com sua família biológica.

Tenho a impressão que minha mãe teria preferido um neto nascido de uma filha [biogenética]. Sei que é apenas uma idéia na minha cabeça, que não é, na verdade, o que ela pensa. Mas é o que sinto. E minha mãe de nascimento mal me conhece, então o nenê tampouco me liga a ela.

Alguns dias mais tarde, visitei a segunda mulher, Birgitta, que foi adotada na Etiópia no início dos anos 70. A filha de Birgitta nasceu em março e, enquanto estávamos sentadas no seu confortável apartamento em Estocolmo, tomando suco de framboesa e comendo doces comprados na padaria do primeiro andar, sua filha dormia tranqüilamente, amarrada às suas costas, no pano que a conectava ao corpo da mãe. Birgitta me falou da sua última viagem a Addis, realizada com o marido Peter, alguns 
Parentesco reconfigurado no espaço da adoção

meses antes do nenê nascer, para visitar o hospital onde sua própria mãe tinha morrido logo depois do parto. Descreveu o medo que tinha, ao dar à luz a um bebê em Estocolmo, de também, talvez, não sobreviver à experiência e relatou a alegria que sentiu depois da filha ter nascido ao se dar conta de que ainda estava viva.

Essas duas histórias não são representativas, mas iluminam o trabalho envolvido na fabricação do parentesco (Carsten, 2001), quer seja o parentesco considerado "biogenético" ou "adotivo". No primeiro caso, Katarina começou a pensar em engravidar depois de uma longa e obstinada busca pela mãe de nascimento, seguida por um encontro em que o gesto desta mãe parece ter afirmado a ligação de Katarina com ela "por nascimento". No entanto, quando engravidou, ela optou por uma forma de parto $e$ de alimentação da criança que evocava sua relação com a mãe adotiva (que não pôde nem parir nem amamentá-la). Apesar desse esforço de "conectar-se" (como ela mesma fala) não dar certo e de acreditar que sua mãe adotiva teria preferido um neto biogenético, Katarina implicitamente aceitou a idéia de que conexão requer trabalho (não é um dado biogenético). Da mesma forma, acreditou que não poderia (ainda) conectar-se com sua mãe de nascimento, porque não a "conhecia" o suficiente. Ela estava planejando voltar ao Chile com sua filha quando esta estivesse mais velha. ${ }^{2}$

Para Birgitta, a segunda mulher, visitar o hospital onde sua mãe tinha morrido durante o parto, enquanto ela mesma estava grávida, pode ser visto como uma outra maneira de realizar o parentesco - neste caso, conectando-a, para trás, à sua mãe biológica e, para frente, ao filho por nascer. Aqui, o trabalho do retorno (ao hospital) torna-se base para a criação desses elos, a partir dos quais ela poderá se situar no mundo. A criança dada (Birgitta) e a criança guardada (a que ela daria à luz) convergem

2 Ver a observação de Carsten (2000:693): "Ties to birth kin required time as a necessary but not in itself sufficient input to establish themselves". 
metafórica e materialmente nesse momento. A presença de seu marido (o pai da criança) também contribui para "fazer" essa família, um processo em que a conexão da Suécia com a Etiópia toma corpo na volta de Birgitta, traduzindo-se pelo ato de dar à luz uma criança ao mesmo tempo sueca e etíope.

Essas narrativas sublinham o poder de discursos de "sangue" ou conexão "biogenética" nas práticas de parentesco adotivo e, ao mesmo tempo, apontam para os tipos de trabalho envolvido na produção de novas formas de conexão (relatedness). No caso de Katarina, o encontro longamente planejado com a mãe biológica e a opção por uma maneira, aparentemente, menos "natural" de parir e de amamentar sua filha "biogenética" constituem o chão a partir do qual ela tenta reconfigurar uma experiência de parentesco com sua mãe adotiva. Por outro lado, Birgitta, ao voltar com o nenê na barriga para o lugar onde ela mesma foi dada estabelece o terreno relacional de parentesco com sua mãe biológica e com sua (futura) filha. Nos dois casos, desconstrói-se o contraste - sangue versus conduta ou lei - que subjaz à distinção entre parentesco biogenético e parentesco adotivo. Reconhece-se o poder do sangue, mas apenas para que essas pessoas adotadas reelaborarem os significados convencionais dessa noção.

\section{"Sendo biológico" ou "como eles"}

Nos parágrafos que se seguem, inspiro-me em pesquisas realizadas na Suécia, Índia, Colômbia, Equador, Bolívia, Chile e nos Estados Unidos entre 1995 e 2004 para enfocar o que Laurel Kendall (supracitada) descreve como "a plasticidade assim como a força do parentesco idiomático" no contexto da adoção transnacional. Essa forma de adoção começou no fim dos anos 50 $e$ início dos anos 60, numa época em que no mundo hiperdesenvolvido as taxas de nascimento estavam em queda, diminuindo o número de crianças disponíveis para adoção doméstica. Criou-se, assim, uma abertura potencial para crianças 
Parentesco reconfigurado no espaço da adoção

oriundas do chamado "mundo em desenvolvimento" passarem a ser recursos para indivíduos e casais que queriam se tornar pais $e$ não podiam (ou não queriam) parir um filho. A adoção transnacional foi conceituada por seus protagonistas como uma maneira de, simultaneamente, resolver problemas de desejo (por uma criança) e necessidade (de uma família), mas nos dois casos a solução - "a família" - era a mesma.

A Convenção de Haia sobre Adoção Internacional (1993), assim como a adoção doméstica em muitos países euroamericanos, é baseada no princípio exclusivista, descrito por Duncan como o modelo "ruptura limpa" do parentesco adotivo. A filosofia exclusivista subjaz ao que conhecemos como adoções plenas ou "fortes", que envolvem "a integração total da criança na família adotiva e o corte de laços com a família biológica" (Duncan, 1993:51; Hollinger, 1993). O apagamento do parentesco biogenético e a construção de uma família adotiva no seu lugar produzem o que Modell (1994) chama de famílias as-if ou "como se" (como se fossem biogenéticas). Nos Estados Unidos, a família adotiva goza do status "como se", graças à política de segredo envolvendo práticas tais como o sigilo de registros hospitalares do parto e da certidão original de nascimento e a emissão de novas certidões como se a mãe adotiva fosse a mãe biológica.

Na Suécia onde, a partir de 18 anos, adotados têm livre acesso aos seus registros, as adoções domésticas (que, embora atualmente sejam raras, eram comuns até os anos 60) tendem a se tornar invisíveis e pesquisas recentes revelam as tensões e silêncios que circundam as origens familiares da criança adotada. ${ }^{3}$ Como nos Estados Unidos, o conceito de laços de sangue (blodsband) é, também na Suécia, um signo poderoso de pertencimento. Como as políticas de bem-estar na Suécia fornecem amplo apoio para mães e crianças, incluindo generosas licenças de maternidade $(e$

${ }^{3}$ Matwejeff (2004:137) nota que adotados na Suécia dizem que "durante a infância, a adoção e a questão de suas origens são assuntos delicados para a família adotiva, com elementos de irritação e silêncio"; ver também Landerholm, 2003. 
paternidade), cuidados gratuitos de saúde e educação gratuita, assim como acesso fácil à contracepção e aborto legal, é pouco provável que crianças nascidas no país sejam entregues para adoção. Nos casos em que assistentes sociais consideram ser de interesse da criança removê-la dos cuidados da mãe de nascimento, a política corrente não abole os direitos parentais, mas coloca os filhos em famílias de acolhimento (de curta ou longa duração); a mãe acolhedora deve encorajar o relacionamento contínuo entre pais biológicos e filho. Nos raros casos em que uma mulher pede para seu filho ser dado em adoção, as assistentes sociais podem até tentar desencorajá-la (Barth, 1992:40-41). ${ }^{4}$

Tanto na Suécia como nos Estados Unidos, adoções transnacionais (que tendiam a ser transraciais a partir do fim dos anos 50, já que a maioria das crianças adotadas vinha da Ásia, América Latina e, de forma menos freqüente, África) complicam o projeto de produzir uma família "como se", já que em muitas dessas adoções a "diferença" entre os pais adotivos e a criança é evidente. ${ }^{5}$ Conforme um panfleto editado nos anos 90 pelo Comitê pela Adoção Internacional (NIA) do governo sueco para a orientação de pais adotivos,

\begin{abstract}
Atualmente, nossos filhos adotivos têm em geral uma aparência diferente do tipo nórdico mais comum... Adoção significa que a criança com sua aparência [diferente] anunciará para o mundo um fato que continua a ser muito sensível: que o casal não podia ter um filho biológico (NIA, n.d.:21-22, tradução livre).
\end{abstract}

Adoções transnacionais podem intensificar as tensões entre uma família "real" ou "natural" e uma família adotiva, quando

\footnotetext{
4 Para uma discussão das políticas de proteção à infância na Suécia, ver também Gould, 1987; Andersson, 1990; Weightman \& Weightman, 1995.

${ }^{5}$ Para dados sobre adoção em países que enviam e os que recebem crianças adotadas, ver Selman, 2005.
} 
Parentesco reconfigurado no espaço da adoção

sublinham a conexão entre laços de "sangue" e uma identidade nacional racializada nos países euro-americanos. ${ }^{6}$ Ao mesmo tempo, como tentarei mostrar a seguir, a figura do adotado complica essa imagem de identidade nacional.

Na Suécia, a adoção transnacional contribuiu para crescentes tensões raciais associadas às populações imigrantes nos anos 70 e 80, ao mesmo tempo em que forneceu um potencial para a intervenção. Essas tensões pioraram à medida que terminou o período de prosperidade pós-guerra, no final dos anos 60 na Europa Ocidental, e desapareceram programas que encorajavam a imigração de trabalhadores estrangeiros, concluindo uma fase descrita, na Suécia, como a transição "gradual" para uma nação multiétnica e multicultural. Nas três décadas seguintes, refugiados do Chile de Allende, curdos nacionalistas, somalis e bósnios substituíram os chamados migrantes "econômicos" do Oriente Médio, gerando o "súbito" surgimento da Suécia "multiétnica" (Christopher Caldwell, 2006:56). À medida que um crescente número de refugiados de nações nãoeuropéias procurava asilo na Suécia nos anos 70 e 80, criando o que um observador descreveu como "um pânico moral induzido pela mídia", com imagens da Suécia sendo ameaçada por uma “'invasão' ou 'inundação incontrolável' de refugiados”, a criança adotada veio a representar a imagem de uma Suécia bemsucedida no seu projeto de nação multicultural (Pred, 2000:43).

\footnotetext{
6 A adoção "transnacional", "internacional" ou "entre países", termos usados de forma intercambiável em boa parte da literatura sobre adoção, foi identificada como adoção transnacional apenas na última década. A terminologia é reveladora, pois diferencia adoções transnacionais domésticas (em que o termo "transracial" referia-se em geral à adoção de crianças afro-americanas por pais "brancos" - um processo altamente controvertido) das colocações aparentemente menos problemáticas de crianças atravessando fronteiras nacionais. Na Suécia, muitos pais adotivos e funcionários de agências de adoção ainda resistem à idéia de que adoções transnacionais representam uma forma de adoção transracial. Um dos meus objetivos neste trabalho é sugerir como o transnacional pode ser concebido como transracial, sem reificar a identidade racial da criança adotada.
} 
Na Suécia dos anos 70 e 80, a figura do adotado foi concebida como radicalmente diferente dos "suecos" por fora, mas como helsvensk (completamente sueco) por dentro graças às capacidades dos pais suecos. Numa série de artigos no jornal do Centro de Adoção - a maior organização sueca para a adoção nos anos 70 e 80 -, a criança adotada era vista como vinda de uma cultura "incrivelmente diferente" (Etiópia, Coréia, Índia) e chegava na Suécia "talvez para a sua primeira família". Era contrastada com a "criança imigrante", cujas diferenças resultavam de sua "situação familiar e vida em casa" que, presumia-se, permaneciam "turcas" (estereótipo do imigrante em meados do século XX na Suécia) quando a família se mudava para Estocolmo ou Goteborg (Kats, 1975:124).

A idéia de que a criança adotada poderia ser transformada em uma criança "completamente sueca" (Andersson, 1991:2) foi desmentida à medida que a primeira geração de adotados chegava à maturidade. Adultos adotados descrevem suas experiências de racismo na escola e sua percepção nascente de que eram "diferentes" e poderiam ser vistos como imigrantes. Sara Nordin, adotada da Etiópia em 1969, explicou essa transição:

Meus pensamentos sobre esse tipo de coisa começaram quando eu tinha 14 ou 15 anos, porque havia muitos problemas raciais na minha escola. Era uma escola com muitos imigrantes. Portanto, tinha muito - a polícia ficava lá, tinha muita briga. Então, fiquei numa situação esquisita, porque quase me tornei imigrante, apesar de sentir-me muito sueca (jattesvensk). Os imigrantes achavam que eu era como eles. E meus amigos suecos achavam que eu era como eles. E eu não conseguia decidir a que lado pertencia. Era muito difícil porque as pessoas implicavam muito comigo. Quando eu era pequena, dava para punir esses caras. Mas no colégio ficou mais sério... E então comecei a pensar sobre tudo isso, mas era tudo muito deprimente. Não tinha nenhuma graça. ${ }^{7}$

${ }^{7}$ Entrevista em Estocolmo, Suécia, agosto 1999, em sueco. 
Parentesco reconfigurado no espaço da adoção

Outra adulta adotada, nascida na Coréia do Sul, descreve sua relação conflituada com imigrantes durante sua juventude num subúrbio de Estocolmo nos anos 70:

Acredito que é, sem dúvida, mais fácil ser adotada da Coréia do Sul do que da Etiópia. Por exemplo, uma aparência coreana não é associada a refugiados. Se alguém vê um iraniano, pensa imediatamente "refugiado". Todo mundo que me vê entende que sou adotada, ou uma imigrante voluntária que trabalha e faz sua parte. É uma boa sensação, porque senão é como se eu tivesse ficado de fora. Não me sinto confortável na presença de imigrantes, porque acho que, de certa forma, eles atrapalham a imagem que tenho de mim mesma como sueca. Eles me lembram que eu, também, sou um tipo de imigrante, embora eu sinta que não sou, porque não quero ver as coisas assim. Hoje posso lidar com isso. Era pior dez anos atrás, quando os imigrantes começaram a chegar a Skelleftea (von Melen 1998:163).

A experiência de adotados como estes ecoa na preocupação de pais adotivos e profissionais no Centro de Adoção, de que a "criança adotada" - mais do que simplesmente ser vista como diferente - possa ser diferente. O que acontece, pergunta Madeleine Kats, psicóloga e ex-diretora do Conselho do Centro de Adoção,

se somente nós recebemos uma criança que não é como nós e que não se torna como nós - uma criança que não somente parece diferente, mas que, de fato, é diferente e sempre será assim? [e sugere que os pais repensem] em que termos adotamos (Kats, 1990:9).

Pesquisas sobre a adaptação de suecos adotados durante os anos 80, citando a literatura mais antiga na Inglaterra sobre a importância de integrar o passado com o presente na vida de uma criança adotada, advertem para os problemas potenciais causados 
pelo esforço exagerado de "suequizar" a criança adotada (att forsvenska barnet), sugerindo que o tiro pode sair pela culatra (Cederblad, 1984; Cederblad et alii, 1994).

O debate sobre esse "problema" - a identidade do adotado e seu pertencimento à nação adotiva - tornou claro certos pressupostos sobre a criança (adotada) e sua "natureza" recalcitrante. Essas preocupações lembram a discussão feita por Marilyn Strathern (1988:104) sobre a lógica de noções euroamericanas de identidade, nas quais as pessoas são vistas como possuidoras de certas "propriedades", que lhes "pertencem" num sentido definicional $e$ que constituem o possuidor enquanto "entidade unitária social". As pessoas "são o que têm ou o que fazem. Qualquer interferência nessa relação um-a-um é vista como a intrusão de um 'outro'" Da mesma forma que o indivíduo é, supostamente, dono de sua própria pessoa, a sociedade é vista como "possuidora" das propriedades (i.e., as pessoas) que intrinsecamente a constituem. A transferência de uma criança de um "dono" para outro (de uma família ou nação para outra) perturba essa relação entre produto e produtor - entre uma nação e "seus" cidadãos, entre pais e "seu" filho, entre uma pessoa e sua "natureza". Na lógica de comodificação, o afastamento deste chão de pertencimento produz um sujeito alienado, que será, inevitavelmente, puxado "de volta" ao lugar ao qual realmente pertence.

Debates entre representantes de nações doadoras $e$ recebedoras de crianças, na Conferência de Haia sobre a Adoção Internacional, foram orientados por essas formas rivais de compreender a identidade de uma criança adotada. A criança era representada como um "recurso" nacional e natural dos países que a doavam (Carlson, 1994) e a versão final da Convenção da Haia (1993) incluiu disposições que colocavam a adoção transnacional como última opção para crianças "abandonadas", recomendando, antes, a reintegração familiar ou uma família adotiva no país de nascimento. A adoção transnacional só era preferível à institucionalização em orfanatos. Essa abordagem dos 
Parentesco reconfigurado no espaço da adoção

direitos da criança abandonada é baseada na Convenção dos Direitos da Criança das Nações Unidas (de 1989), que estipula o direito da criança a um nome, a uma família e ao pertencimento nacional. Porém, esses direitos não são limitados ao país ou à família de nascimento (artigo 8). Na Convenção de Haia, tensões entre nações "doadoras" e "recebedoras" em torno deste assunto desembocaram numa série de cláusulas conflitantes. O artigo 4 estipula o "término da relação legal entre a criança e sua família de origem" e o artigo 18 regula a mudança na residência permanente da criança. Entretanto, ao decidir onde colocar a criança, o artigo 16 prescreve a "devida consideração quanto às suas origens étnicas, religiosas e culturais" e o artigo 30 exige a preservação de informações sobre as origens da criança. Ao mesmo tempo, a Convenção da Haia endossou certas ficções legais que subjazem à adoção - doméstica ou internacional - de uma criança: a idéia de que as crianças são órfãs, ou de que seus pais consentiram voluntariamente em entregá-las para adoção, torna essa entrega "irrevogável" e a adoção produz uma ruptura limpa com o passado. Dessa forma, a criança adotável era construída como autônoma (freestanding), "parte de um estoque (anônimo) do qual outras pessoas lançam mão" (Strathern, 1997:302). ${ }^{8}$ A transformação legal de uma criança cujas propriedades "naturais" eram moldadas por seus pais hindus, etíopes, coreanos ou colombianos em uma criança autônoma faz parte da mesma lógica de comodificação que postula uma identidade singular - completamente sueca ou completamente etíope, coreana, etc. As próprias premissas sobre as quais constróise a política liberal de adoção legal pressupõem uma criança que só pode ser uma coisa ou outra e cuja disponibilidade para adoção exige a anulação de uma identidade, permitindo sua substituição por uma outra. As experiências de suecos adotados nos anos 70 e 80 e de suas famílias adotivas sugerem que o cancelamento legal não produziu uma tabula rasa a partir da qual

8 Sobre esse assunto, ver também Yngvesson, 2002. 
seria possível transformar a criança em uma pessoa "completamente sueca", e sim que a história da criança deixava marcas que iam assombrar a família e a nação adotivas.

Minha pesquisa de adoção transnacional começou pouco tempo depois da reunião de Haia em 1993, numa época em que a Suécia, há muito país promotor das regulações internacionais que protegem os direitos de crianças, estava começando a repensar suas políticas de adoção à luz da Convenção. Nessa reavaliação, certas questões eram centrais: a conexão da criança adotada com "sua cultura" (e, afinal, com sua família original), a atenção cada vez maior a viagens para resgatar raízes e (da parte de psicólogos $e$ assistentes sociais) a importância de integrar a mãe de nascimento na história adotiva da criança (Stjerna, 1976; Cederblad et alii, 1994). Essa "integração" (advogada por Ingrid Stjerna, assistente social de Estocolmo com mais de três décadas de experiência com adoção transnacional) envolve, no mínimo, aceitar o fato de que, como aponta Stjerna, "não existe criança sem mãe - mesmo se [esta] já morreu, ela ainda é importante". Como resultado, sustenta Stjerna, a criança adotada "não é realmente sua [dos pais adotivos] criança". ${ }^{9}$ Nesse sentido, a criança não pertence aos pais biogenéticos, mas sua identidade é produzida na passagem de um lugar (um pai ou mãe) para outro $e$ essa história molda sua "natureza".

Em um pequeno (mas, a julgar por algumas evidências, crescente) número de casos, a integração da mãe de nascimento na família adotiva pode significar muito mais do que aceitar sua realidade existencial para a criança adotada. Pode significar encontrá-la (e possivelmente encontrar outros membros da família de nascimento da criança) e travar uma relação ativa com esses parentes legalmente inexistentes - irmãos, primos e avós, além dos pais de nascimento. Em certos casos, essas reuniões evoluíram

9 Stjerna falava para um grupo de colegas russos do Centro de Adoção que realizavam uma visita em agosto de 1999 (apud Yngvesson, 2005:43). 
Parentesco reconfigurado no espaço da adoção

para visitas regulares, geralmente do adulto adotado à sua família de nascimento, mas há visitas também na outra direção.

Ingrid Stjerna sustenta que aceitar a mãe de nascimento é um dos desafios mais difíceis que os pais adotivos devem superar: "Origens e país e decorações e canções - tudo isso é ótimo, mas a mãe não". ${ }^{10}$ Entrevistas com adultos adotados e com pais adotivos na Suécia e nos Estados Unidos, assim como observação participante, confirmam a experiência de Stjerna nesta questão. Amanda Fredriksson, adotada na Etiópia nos anos 70, fez diversas viagens de volta para visitar sua família estendida de nascimento. No entanto, ela explica que não é fácil para sua família sueca, $e$ para sua mãe sueca em particular, entender as viagens, tornandose um assunto "carregado" (laddat). A terceira vez que ela foi, sua mãe perguntou, "'Por que tu queres ir?' Ela realmente não entendia por que eu continuava a fazer essas visitas. Ela disse, 'Por que ir de novo? O que tem de tão bom?'”. Somente depois da quarta viagem, sua mãe explicou ter presumido que aquela primeira viagem, quando Amanda ainda era uma adolescente acompanhada pelos pais adotivos, seria a única. Quando retornou mais uma vez, cinco anos mais tarde, sua mãe a alertou para o

perigo de se tornar obcecada por meus sentimentos e pela Etiópia (Att jag skulle fastna fast i mina kanslor och Etiopien). Mas contei para ela que não poderia ficar obcecada. É uma realidade em que vivo. Não estou criando algo que não existe. ${ }^{11}$

A "realidade em que vivo", para adotados como esta mulher, é formada, em parte, pelas experiências de racismo que os situam fora do pertencimento na Suécia. Essas experiências incluem identificação com imigrantes, crescentemente isolados em

${ }^{10}$ Ver também Yngvesson, 2002. Stjerna $(1975,2006)$ tem insistido repetidamente nesse recado para pais adotivos, verbalmente e em publicações, durante, pelo menos, os últimos 30 anos.

${ }^{11} \mathrm{AF}$, entrevistas em Estocolmo em agosto, 1999 e agosto, 2002, em espanhol. 
loteamentos segregados, que marcam as fronteiras da sociedade civil na Suécia (Rojas, 1995; Pred, 2000; Caldwell, 2006), e o fato de ser alvo de atitudes ofensivas que os associam a categorias aviltantes ("neger" ou "chingchong") (von Melen, 1998:67). ${ }^{12}$ A "realidade em que vivo" também inclui todos os pressupostos sobre família na Suécia, nos quais os laços de sangue são uma consideração central. Como notou Sara Nordin:

Quando chega aqui [na Suécia] a gente se sente um pouco só nessa situação, mas lá [na Etiópia] - é difícil colocar isso em palavras - tem tanta coisa ao teu redor, tem tanta coisa acontecendo. Ter sido adotada ou abandonada não é grande coisa lá. Mas aqui na nossa sociedade é enorme.

[Amanda Fredriksson acrescentou]

Os amigos e contatos que temos lá, muitos vivem em grandes famílias, com primos e vizinhos e muitas pessoas que não são ligadas por sangue. Então dizem, "Jaha, esse aqui também é meu irmão, embora não seja meu verdadeiro irmão". Mas aqui, as pessoas têm muito cuidado sobre esse tipo de coisa: "E você parece com quem? E quem é teu?" Dessa forma a gente lembra o tempo todo que não somos biológicos. Lá, tem pessoas, mesmo se não somos família, somos parecidos com eles. Mas aqui a gente é parecida com poucos.

Aqui existe um contraste entre as categorias, por um lado, "relacionados por sangue" e "biológico" ou "família", por outro, "não relacionados por sangue" $e$, no entanto, "parecidos com eles". Existe também uma ambiguidade no significado de "parecido": "parecido" enquanto "adotado ou abandonado, não

\footnotetext{
${ }^{12}$ von Melen sublinha a hierarquia de valores presente nessas categorias, nas quais "neger" é mais acusatório, enquanto "chingchong" é mais brando. As pessoas adotadas que entrevistei, assim como pesquisas realizadas por outros pesquisadores, como von Melen, sugerem que os adotados da América Latina, muitos dos quais têm pele mais clara, encontram menos dificuldades com racismo na Suécia.
} 
Parentesco reconfigurado no espaço da adoção

é grande coisa lá" ou "parecido" enquanto fisionomia-cor-neger. Juntos, sugerem a plasticidade e a força do "sangue" e de sua capacidade de reproduzir parentesco biológico ao mesmo tempo em que engloba outros significados. ${ }^{13}$ Como nas histórias de Katarina e Birgitta, o parentesco biogenético é, ao mesmo tempo, realizado e complicado, porque começa como uma busca ou "volta" às origens. ${ }^{14}$

Um exemplo parecido é fornecido pelo filme autoetnográfico de Deann Borshay Liem, First Person Plural (2000). Liem conta seus esforços para encontrar sua família coreana da qual fazia parte antes de ser colocada num avião rumo a uma família adotiva nos Estados Unidos em meados dos anos 60. Liem, cujo nome coreano era Kang Ok Jin, tinha sido colocada temporariamente por sua mãe num orfanato perto de casa, depois que seu pai morreu, e foi enviada para os Estados Unidos pelo diretor do orfanato sem o consentimento da mãe. De fato, foi enviada no lugar de outra criança, Cha Jung Hee, que foi repentinamente retirada do orfanato logo antes de embarcar para os Estados Unidos. Aos oito anos Liem chegou aos Estados Unidos com o nome e história de Cha Jung Hee, com documentos que a identificavam como órfã. Assim que pôde, explicou para sua família adotiva que não era órfã e que tinha uma família. No entanto, ouviu deles que essa era uma fantasia muito comum entre crianças adotadas e foi esquecendo sua primeira família, a língua coreana, e parecia ter se integrado plenamente na sua família e na escola na Califórnia. Muitos anos mais tarde, assombrada por pesadelos e sofrendo de depressão, ela voltou ao seu arquivo de adoção e descobriu fotos de duas meninas diferentes com idade de oito anos, as duas com nome de

\footnotetext{
${ }^{13}$ Ver a discussão de Stuart Hall (1997:50) da noção de Derrida (1978:279) sobre "o traço de algo que ainda retém suas raízes em um significado enquanto está, de certa forma, mudando para outro, encapsulando um outro...".

${ }^{14}$ Para uma crítica do conceito de "retorno" no discurso do campo de adoção, ver Yngvesson e Coutin, 2006.
} 
Cha Jung Hee, mas somente uma correspondia à pessoa que se tornaria Deann Borshay.

Liem escreveu ao orfanato e, algumas semanas depois, recebeu uma carta de seu irmão na Coréia, confirmando sua identidade de Kang Ok Jin e informando-lhe que, além de seu irmão, ela ainda tinha uma mãe e duas irmãs morando na Coréia. Liem viajou para a Coréia do Sul para encontrá-los e, mais tarde, arranjou a viagem que levou seus pais adotivos a visitar sua família de nascimento - cena registrada no filme. O filme enfoca a luta de Liem para conciliar seus sonhos e suas lembranças da mãe $e$ dos irmãos que deixara na Coréia com a realidade do relacionamento que estabeleceu com seus pais adotivos. Durante toda a reunião das duas famílias, apesar da ligação emocional muito forte, especialmente entre Liem e sua mãe de nascimento $e$ entre Liem $e$ as suas duas irmãs mais velhas, estava claro que existem diferenças que não são facilmente transpostas. De forma semelhante, a visita parece materializar um relacionamento de maior profundidade com sua mãe adotiva. No final do filme, Liem expressa o sentimento que sua "verdadeira" mãe é sua mãe adotiva, mas também a convicção de que é somente ao se dar conta que sua mãe de nascimento "não é minha mãe" que ela poderá desenvolver um relacionamento com ela.

Aqui, a busca bem-sucedida pela mãe de nascimento "realiza" a mãe adotiva e, ao mesmo tempo, transforma o parentesco imaginado com a mãe biogenética para que um tipo diferente de relação possa ser estabelecido. Em outro caso, Kim Hyo Jin, uma criança da Coréia adotada aos oito anos de idade por uma família de New Jersey, passando a ser conhecida como Jaclyn Campbell Aronson, voltou para encontrar sua mãe de nascimento aos 22 anos. Aronson, que goza de grande intimidade com sua mãe adotiva, considera sua mãe de nascimento como mãe de Kim Ho Jin, "a menininha que nunca pôde crescer além de oito anos de idade" (Aronson, 1997:30). Aronson continua a manter um relacionamento com essa mãe anterior, baseado no fornecimento de apoio econômico e nas suas lembranças da 
Parentesco reconfigurado no espaço da adoção

criança coreana que continua a estar simbolicamente "dentro dela", mas o relacionamento é ativado pela força de sua ligação à família adotiva e pelo seu apoio aos laços complexos e dolorosos que ela mantém com a Coréia.

\section{"Estrela Fúlgida"}

Até aqui, centrei a discussão nas maneiras em que um relacionamento entendido como fundamentado no "sangue" é concebido e realizado no relacionamento "adotivo", particularmente no contexto de relações pais-filhos. No entanto, a plasticidade do parentesco idiomático na adoção transnacional se manifesta também de outras formas. Na Suécia, assim como em outros países adotantes, os adotados formaram uma variedade de redes informais de apoio e também de organizações formais, muitas vezes organizadas em torno da identidade nacional. Em Estocolmo, duas das organizações mais ativas são a Associação de Coreanos Adotados (AKF) e a Associação de Etíopes e Eritreus Adotados (AEF). Esta última, com a qual tive contato através de entrevistas com diversos adultos adotados, incluindo seu organizador, Daniel Rosenlind, foi fundada em meados dos anos 90 e ofereceu um tipo de rede de segurança aos seus membros. Uma mulher, ativa na organização desde o início, disse que as reuniões acontecem em um restaurante de Estocolmo, um espaço onde

não é preciso explicar, apresentar e contar... dá para simplesmente fazer parte. Ainda por cima, dá para ouvir outras experiências e conhecer variações sobre o mesmo tema.

Para alguns membros do grupo, o interesse maior é a Etiópia, para outros, o problema principal é ser negro na Suécia. Daniel explicou: 
Barbara Yngvesson

Quando penso "negro", penso que tenho mais em comum com pessoas da Colômbia. Mas depois penso que tem diferentes tipos de negros, com status diferente. Penso em americanos negros, por exemplo. São legais, são americanos. Tem muitos brancos - especialmente entre os jovens, jovens turcos, por exemplo - que os admiram. Mas se você é de Gâmbia, por exemplo, não é tão legal. Se é das Índias Ocidentais também pode ser bom. Pode ter cabelo rastafari. Tem uma escala que distingue um tipo de negro de outro. Mas, ao mesmo tempo, sinto que tenho muito em comum com todos os negros.

Aqui, uma organização que se desenvolveu com base na identificação nacional de cada membro como "procedente da" Etiópia tornou-se um veículo para estabelecer parentesco com outros que se identificam como "negros" na Suécia. Ao mesmo tempo, conforme me disse um terceiro membro da organização, Mikael Jarnlo, depois de uma das reuniões mensais, o ponto em comum - nascimento na Etiópia e um sentimento de parentesco com outros negros na Suécia - é complexificado por diferenças regionais de ser sueco, porque ele pode ser facilmente identificado como alguém que vem de Skane, no Sul da Suécia, enquanto outros vêm de Estocolmo ou de outras cidades mais ao norte.

A AEF também esteve ativa em uma arena mais global, através de suas ligações com a "Estrela Fúlgida", organização fundada em Addis Ababa por Gizachev Ayka, que procura informar e ensinar adotados etíopes sobre seus pais de nascimento e ajudá-los em reuniões com a família de nascimento. Ayka é irmão de oito crianças que foram adotadas no exterior antes de ele nascer. Em artigo sobre esta organização no boletim mensal publicado pelo Comitê Sueco de Adoções Internacionais (MIA), Ayka explicou que, durante sua infância, seus pais falavam de seus irmãos adotados e mostravam fotos. Ele frisa que os etíopes, cujas crianças foram adotadas no exterior, são pobres e entendem que, ao dar seus filhos em adoção, estão lhes propiciando uma vida melhor. Assim, muitas vezes, quando esses filhos voltam (o 
Parentesco reconfigurado no espaço da adoção

que aconteceu com sete de seus irmãos e irmãs adotados), seus pais

querem ter certeza que fizeram a coisa certa. Querem recompensa. É uma questão cultural. Esperam de meus irmãos adotados o mesmo que esperam de mim. Em termos lógicos, é correto que os pais fizeram a coisa certa para seus filhos. Planejaram o melhor. É difícil para os adotados. Depois que encontram suas famílias e se sentem felizes por essa reunião, a próxima etapa é que devem ajudar sua família (apud Sammarco, 2003:6, tradução livre).

Apesar de elogiar o compromisso de Ayka de ajudar adotados adultos para visitar a Etiópia, Jarnlo é cauteloso quanto a alguns de seus objetivos e ao nacionalismo etíope em geral. Jarnlo descreve sua experiência positiva quando visitou a Etiópia em 1992 pela primeira vez, ressaltando como foi rapidamente assimilado como "etíope".

O mero fato de você fazer contato com eles e demonstrar interesse, eles acham que isso é tão fantástico, e pensam:

"Bem, você obviamente é etíope e deve aprender a falar a língua, deve se casar com uma mulher etíope".

Embora ele se sentisse etíope, Jarnlo acrescentou que isso não mudava o fato de ele ser "antes de tudo sueco" e fez grandes ressalvas à idéia de que os adotados adultos deveriam se sentir responsáveis pelo sustento de suas famílias de nascimento: "Ter sido abandonado e depois ter gente esperando que você ajude os pais abandonantes é esperar demais de um adotado".

Outros adultos adotados nascidos na Etiópia expressam opiniões diferentes sobre o que é, de fato, uma prática semelhante à das remessas enviadas das associações de imigrantes nos Estados Unidos para suas cidades natais, contribuindo de forma significativa para a economia local de uma série de países da América Latina. Uma associada da AEF, que entrevistei diversas 
vezes no decorrer dos últimos sete anos, e que visitava periodicamente sua grande família estendida na Etiópia, não se incomoda de fazer contribuições ocasionais para algum projeto particular (trocar o telhado da casa, por exemplo) que exija esse esforço. Porém, ela descreve outra associada da AEF como alguém que se tornou "uma espécie de banco" na sua relação com a família de nascimento.

Os laços estabelecidos por adotados sueco-etíopes entre si $e$ com irmãos, na Etiópia, e de outros adultos que, como eles, foram adotados no exterior é uma das maneiras pelas quais o parentesco idiomático (como blodsband na Suécia ou como pertencimento nacional na Etiópia) é afirmado e transformado através da adoção transnacional. Talvez o esforço mais ambicioso nesse sentido encontre-se entre adotados adultos da Coréia, cujo engajamento ativo através da internet e nas grandes reuniões transnacionais em Washington D.C. e Seul uniu adotados da Europa, América do Norte, Austrália e Nova Zelândia em um movimento global poderoso, que está levantando questões sobre a natureza de parentesco, laços biológicos e pertencimento nacional (E.Kim, 2005). A possibilidade desse movimento, que aspira constituir uma comunidade transnacional de adotados, é conseqüência, por um lado, do reconhecimento, no fim dos anos 90 da parte do estado coreano, de uma política nacional de adoção formalizada em 1961, que levou a um programa de adoção por estrangeiros, superando o de qualquer outra nação nos últimos 40 anos: mais de 200000 crianças da Coréia do Sul foram adotadas desde o início da adoção por estrangeiros nos anos 50 (Kim, 2005). Esse reconhecimento foi marcado simbolicamente por um convite do Presidente Kim Dae Jung, em 1998, a adotados adultos de muitos países ocidentais para uma visita à Coréia do Sul com todas as despesas pagas pelo governo. O momento alto dessa viagem foi a recepção formal e a cerimônia na Casa Azul, onde o presidente deu boas-vindas aos adotados e desculpou-se formalmente pelo seu exílio de fato. Ele concluiu apresentando a Coréia como a "pátria" deles e os encorajou a "cultivar suas raízes culturais 
Parentesco reconfigurado no espaço da adoção

[porque] a globalização é a tendência da época" (Kim, 1999:16). Nesse sentido, como afirma Eleana Kim em artigo recente, o surgimento de uma comunidade global de adotados coreanos, que procura contestar esse projeto do estado coreano de constituir "uma família global da Coréia" (no qual os adotados coreanos teriam uma participação significativa), em parte, é conseqüência desse mesmo projeto, assim como das tecnologias de informação que facilitam a comunicação entre adotados esparramados ao redor do globo (Kim, 2005:58-60).

Apesar dos esforços de alguns adotados coreanos de se dissociarem dessa família global e se constituírem como pessoas que ocupam um "terceiro espaço" (Hubinette, 2004) ou uma "quarta cultura" que seria fundada "na experiência comum de ser adotado e coreano" (Stock, 1999, apud Kim, 2005:59), "a poderosa sedução das "raízes'" atraiu adotados coreanos para viagens organizadas pelo governo da Coréia do Sul e para "Reuniões" como aquela que ocorreu em Seul em 2005. Além do mais, possivelmente, alguma dimensão dessa "sedução" engendrou o crescimento de organizações de adotados adultos em outros países europeus - Austrália e Estados Unidos. Como sustenta Eleana Kim (2005:59-60),

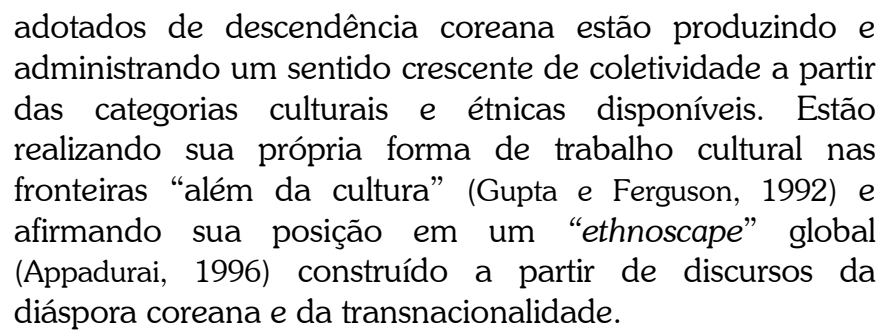

A reconfiguração do parentesco no espaço da adoção transnacional envolve o trabalho de criar conexão em diversos níveis, além dos projetos transnacionais mais amplos de adotados coreanos. Esse trabalho constitui a relação entre pais e criança, cria um "parentesco" entre adotados de um determinado país 
"doador" e que vivem em um determinado país "recebedor", constrói laços entre adotados classificados como "negros" em nações adotivas predominantemente "brancas" e reconstitui laços entre adultos legalmente órfãos e seus irmãos legalmente nãoexistentes que ficaram para trás. Essa reconfiguração remonta ao passado, vai adiante para construir o futuro e, ao mesmo tempo, se alastra "por cima" das fronteiras nacionais, simultaneamente firmadas e minadas pela adoção transnacional durante este último meio século. A reconfiguração incorpora as dicotomias familiares que fazem parte do parentesco euro-americano idiomático ("natureza" versus "nurture", "sangue" versus "lei"; famílias "biogenéticas" versus famílias "adotivas") e, ao mesmo tempo, as retrabalha em maneiras que têm o potencial de criar novas formas de consciência e de transformar as práticas cotidianas de conexão.

\section{Referências bibliográficas}

ADOPTIV BARN VÄXER UPP (Adopted children grow up). Estocolmo, Sweden, Bonniers, 1990.

ANDERSSON, Gunilla. Intercountry adoption in Sweden: The experience of 25 years and 32000 placements. Sundbyberg, Sweden, Adoption Centre, 1991.

ANDERSSON, Gunvor. Barns förhållande till föräldrar och fosterföräldrar (Children's relationship to parents and foster parents). Nordisk Psykologi 42(1), 1990, pp.59-74.

APPADURAI, Arjun. Modernity at Large: Cultural Dimensions of Globalization. Minneapolis, University of Minnesota Press, 1996.

ARONSON, Jaclyn C. "Not My Homeland": A Critique of the Current Culture of Korean International Adoption. Senior thesis, Hampshire College, Amherst, MA., 1997.

BARTH, Richard P. Child welfare servicesin the United States and Sweden: different assumptions, laws and outcomes. Scand. J Soc Welfare 1, 1992, pp.36-42.

CALDWELL, Christopher. Islam on the Outskirts of the Welfare State. The New York Times Magazine, February 5, 2006, pp.54-59. 
Parentesco reconfigurado no espaço da adoção

CARLSON, Richard. The Emerging Law of Intercountry Adoptions: An Analysis of the Hague Conference on Intercountry Adoption. Tulsa Law Journal 30, 1994, pp.243-304.

CARSTEN, Janet. "Knowing where you've come from": ruptures and continuities of time and kinship in narratives of adoption reunions. RJAI 6(4), 2000, pp.687-703.

Sustantivism, Antisubstantivism, and Anti-antisubstantivism. In: FRANKLIN, Sarah and MCKINNON, Susan. (eds.) Relative Values: Reconfiguring Kinship Studies. Durham, Duke University Press, 2001.

CEDERBLAD, Marianne. Följde sin pappa som en skugga (Followed his father like a shadow). Originally published in Att Adoptera, $\mathrm{n}^{\circ} 3$, 1983. Reprinted in Ur Att Adoptera Åren 1979-1983, 1984, pp.3134.

; IRHAMmAR, M.; MerCKe, A. M. and NORLANDER, E. Identitetoch anpassning hos utlandsfödda adopterade ungdomar $\left(\mathrm{n}^{\circ}\right.$ 4). Lund, Sweden, Forskning om barn och familj, Avdelning för barn och ungdomspsykiatri, Lunds universitet, 1994.

DERRIDA, Jacques. Writing and Difference. Chicago, IL., University of Chicago Press, 1978.

DUNCAN, William. Regulating Inter-Country Adoption: An International Perspective. In: BAINHAM, A. and PEARL, D.S. (eds.) Frontiers of Family Law. London, John Wiley \& Sons, 1993.

GoULD, Arthur. "Social Totalitarianism?": Children in care in Sweden and the British media. Policy and Politics 15(1), 1987, pp.29-38.

GUPTA, Akhil and FERGUSON, James. Beyond "Culture": Space, Identity, and the Politics of Difference. In: GUPTA, A. and FERGUSON, J. (eds.) Culture, Power, Place: Explorations in Critical Anthropology. Durham, Duke University Press, 1997.

Hague Convention. Hague Conference on Private International Law, Final Act Of the Seventeenth Session, May 29, 1993, 32 I.L.M. 1134.

HALL, Stuart. Old and New Identities, Old and New Ethnicities. In: KING, Anthony D. (ed.) Culture, Globalization, and the World-System. Minneapolis, University of Minnesota Press, 1997.

Hollinger, Joan H. Adoption Law. The Future of Children 3, 1993, pp.43-61. 
HUBINETTE, Tobias. Adopted Koreans and the development of identity in the "third space". Adoption \& Fostering 28(1), 2004, pp.16-24.

KATS, Madeleine. Är adoptivbarn invandrarbarn? (Are adoptive children immigrant children?). Att Adoptera 6(2), 1975, p.124.

KENDALL, Laurel. Birth Mothers and Imaginary Lives. In: VolKMAN, Toby Alice. (ed.) Cultures of Transnational Adoption. Durham, Duke University Press, 2005.

KIM, Dae Jung. President Kim Dae Jung's Speech: October 23, 1998 at the Blue House. Chosen Child 1(5), 1999, pp.15-16.

KIM, Eleana. Wedding Citizenship and Culture: Korean Adoptees and the Global Family of Korea. In: VOLKMAN, Toby Alice. (ed.) Cultures of Transnational Adoption. Durham, Duke University Press, 2005.

LANDERHOLM, Lotta. Adopterad: Lämnad. Vald. Och Sen? Estocolmo, Alfabeta Anamma, 2003.

LIEM, Deann Borshay. First Person Plural. Ho-He-Kus, NJ, Mu Films, 2000.

MATWEJEFF, Susanna. Svenskfödda adopterades sökprocess (The Swedish-born Adoptees' search process). Linköpings Universitet, Institutionen för beteendevetenskap, 2004.

MODELL, Judith. Kinship with Strangers: Adoption and Interpretations of Kinship in American Culture. Berkeley, University of California Press, 1994.

NIA. Gruppsamtal om adoption. Estocolmo, Sweden, Statens Nämnd för internationella adoptionsfrågor, n.d.

PRED, Allan. Even in Sweden. Berkeley, University of California Press, 2000.

SAMmARCO, Lovisa. The Bright Staren kulturbrygga. NIA informerar 2, 2003, pp.6-7.

StRATHERN, Marilyn. Partners and Consumers. In: SCHRIFT, Alan D. (ed.) The Logic of the Gift: Toward an Ethic of Generosity. New York, Routledge, 1997.

The Gender of the Gift. Berkeley, University of California Press, 1988 [trad. brasileira: O gênero da dádiva. Campinas-SP, Editora da Unicamp, 2006]. 
Parentesco reconfigurado no espaço da adoção

ROJAS, Mauricio. Sveriges oälksade barn: att vara svensk men ändå inte (Sweden's unloved children: to be Swedish but yet not Swedish). Estocolmo, Brombergs.alifornia Press, 1995.

Selman, Peter. Trends in intercountry adoption 1998-2003: A demographic Analysis. Paper presented at the First Global Adoption Conference on Adoption Research, Copenhagen, 9-10 September, 2005.

STJERNA, Ingrid. Biologiska mamman ett hot? (The biological mother a threat?). Att Adoptera 7(3), 1976, pp.100-101.

STOCK, Kimberly K. H. Rise of a Fourth Culture: Korean Adoptees. Transcultured 1, 1999, p.11.

TRISELIOTIS, John. In Search of Origins. London, Routledge and Kegan Paul, 1973.

United Nations Convention on the Rights of the ChiLd. G.A. Res. 44/25, U.N. GAOR, 61 ${ }^{\text {st }}$ plen. Mtg., Annex at art. 21, 1989.

VON MELEN, Anna. Samtal med vuxna adopterade (Conversations with adul adoptees). Estocolmo, Rabén Prisma, 1998.

Weightman, K. and WeightMAN, A. "Never right, never wrong": child welfare and Social work in England and Sweden. Scand $J$ Soc Welfare 4, 1995, pp.75-84.

YNGVESSON, Barbara. Going "Home": Adoption, Loss of Bearings, and the Mythology of Roots. In: VOLKMAN, Toby Alice. (ed.) Cultures of Transnational Adoption. Durham, Duke University Press, 2005.

Placing the "Gift Child" in Transnational Adoption. Law \& Society Review 36(2), 2002, pp.227-256. and Coutin, Susan. Backed by Papers: Undoing Persons, Histories, and Return. American Ethnologist 33(2), 2006, pp.177-190. 